\title{
AUGMENTED REALITY VISUALISASI ANIMASI GAMBAR PADA BAJU DENGAN METODE MARKER-BASED
}

\author{
Kharis Muqowam ${ }^{1)}$, Jati Sasongko Wibowo' ${ }^{2}$ \\ ${ }^{12}$ Teknik Informatika, Unisbank Semarang \\ ${ }^{12}$ Jalan Tri Lomba Juang Semarang \\ Email: ${ }^{1}$ kharisgreat@gmail.com, ${ }^{2}$ jati@unisbank.ac.id
}

\begin{abstract}
Screen printing on clothes so far has only been limited to image designs that are printed and attached to clothes, but there are also people who understand the art of an image and think that screen printing on clothes also has artistic value based on the complexity of the design. Their work is not only underestimated by consumers, so they try to make their screen printing results as close as possible and even exceed the expectations of consumers, because of that many screen printing at this time innovate in various ways to be able to make their screen printing results unique and more attractive. attracting consumer interest, one of which is taking advantage of current technological developments, with AR technology now screen printing results are not only limited to images that only stick to clothes, but a work can turn into something new and unique with AR technology. The development method used in making this application is Prototype whose stages consist of Listen to Customer, Build and Revise Mock-up, Customer Test Drives Mock-up. The system design method uses design tools such as Use Case Diagrams, Activity Diagrams, Sequence Diagrams. The result of the research is the application of AR animated images on clothes using Augmented Reality technology to increase consumer interest in buying clothes
\end{abstract}

Keyword: Augmented Reality, Marker Based, Screen Printing, Animation, Prototype

\section{Abstrak}

Sablon pada baju selama ini hanya sebatas desain gambar yang dicetak dan menempel pada baju, namun ada juga orang yang paham akan seni dari sebuah gambar menganggap bahwa sablon pada baju juga memiliki nilai seni berdasarkan kerumitan pada desainnya, para penyablon sendiri pasti berusaha semaksimal mungkin supaya hasil karyanya tidak hanya di pandang sebelah mata oleh para konsumennya, jadi mereka berusaha membuat hasil sablon mereka bisa semirip mungkin bahkan bisa melebihi ekspetasi dari para konsumen, karena itu banyak penyablon pada masa saat ini berinovasi dengan berbagai cara untuk bisa membuat hasil sablon mereka unik dan lebih menarik minat konsumen, salah satunya memanfaatkan perkembangan teknologi saat ini, dengan adanya teknologi AR kini hasil sablon tidak hanya sebatas gambar yang hanya menempel pada baju, namun sebuah karya tersebut bisa berubah menjadi sesuatu yang baru dan unik dengan adanya teknologi AR. Metode pengembangan yang digunakan dalam pembuatan aplikasi ini adalah Prototype yang tahapannya terdiri dari Listen to Customer, Build and Revise Mock-up, Customer Test Drives Mock-up. Metode perancangan sistem mengunakan tools perancangan seperti Use Case Diagram, Activity Diagram, Sequence Diagram. Hasil dari penelitian adalah aplikasi AR animasi gambar pada baju dengan menggunakan teknologi Augmented Reality untuk meningkatkan ketertarikan konsumen dalam membeli baju

Kata Kunci: Augmented Reality, Marker Based, Sablon, Animasi, Prototype

\section{PENDAHULUAN}

Perkembangan teknologi yang sangat cepat ini berpengaruh besar dengan aspek kehidupan manusia. Teknologi yang ada saat inipun dituntut untuk lebih banyak melakukan inovasi yang semakin mempermudah dan memanjakan konsumenya. Beberapa konsumen merasa tidak puas jika hanya melihat barang yang akan dibeli dalam bentuk gambar. Maka akan dibutuhkan teknologi tertentu pada smartphone android agar konsumen merasa transaksinya seolah-olah nyata. Salah satu contoh terobosan dalam penggunaan teknologi sebagai media informasi adalah dengan Augmented Reality (AR) [1].
Sablon pada baju selama ini hanya sebatas desain gambar yang dicetak dan menempel pada baju, namun ada juga orang yang paham akan seni dari sebuah gambar menganggap bahwa sablon pada baju juga memiliki nilai seni berdasarkan kerumitan pada desainnya, para penyablon sendiri pasti berusaha semaksimal mungkin supaya hasil karyanya tidak hanya di pandang sebelah mata oleh para konsumennya, jadi mereka berusaha membuat hasil sablon mereka bisa semirip mungkin bahkan bisa melebihi ekspetasi dari para konsumen, karena itu banyak penyablon pada masa saat ini berinovasi dengan berbagai cara untuk bisa membuat hasil sablon mereka unik dan lebih menarik minat konsumen, salah satunya memanfaatkan perkembangan teknologi saat ini, 
dengan adanya teknologi AR kini hasil sablon tidak hanya sebatas gambar yang hanya menempel pada baju, namun sebuah karya tersebut bisa berubah menjadi sesuatu yang baru dan unik dengan adanya teknologi AR.

AR merupakan gabungan yang dibuat oleh komputer dari dunia virtual dan dunia asli. Objek virtual terdiri dari text, animasi, bentuk 3D ataupun penggabungan dengan lingkungan aslinya sehingga dirasakan obyek virtual di lingkungannya. Penggunaan AR juga diberikan sentuhan dan pengalaman baru dan sebagai pelengkap dalam tampilan dunia asi [2]. Pada teknologi AR, pengguna diberikan gambaran tentang gabungan antara dunia asli dengan dunia maya dari tempat yang sama [3]. Pada penelitian [4] penggunaan teknologi AR mampu memberikan informasi dalam bentuk audio, sehingga pengguna bisa mendapatakan informasi dalam bentuk visual dan dapat berinteraksi langsung dengan objeknya. AR memiliki kelebihan bersifat interaktif dan real salah satunya digunakan sebagai edia visualisasi animasi gambar pada baju. Penelitian oleh [5] berhasil membuar AR dengan metode Merkeless AR sehingga tidak memerlukan marker kusus untuk menjalankannya. Penelitian oleh [6] berhasil membuat aplikasi AR yang dapat mengajarkan anak-anak alfabet dengan baik dan menghibur. Penelitian oleh [7] membuat aplikasi AR yang dapat digunakan untuk dipahami sejarah \& budaya di Indonesia sehingga dapat dikenal luas.

Dari permasalahan tersebut, gagasan yang dimiliki penulis untuk membuat aplikasi AR. AR memiliki salah satu kelebihan antara lain yaitu dapat mengimpementasikan secara luas dalam berbagai media. Seiring berkembangnya teknologi tersebut, penggunaan teknologi $\mathrm{AR}$ pada proses menggunakan gambar ke dalam bentuk animasi 3D yang menarik untuk bisa membuat hasil sablon yang unik dengan metode Marker Based berbasis mobile Android

\section{METODE PENELITIAN}

\subsection{Metode Pengumpulan Data}

Metode pengumpulan data menggunakan metode studi pustaka melalui pencarian literatur yang terkait dengan teknologi AR menggunakan metode Marker Based.

\subsection{Metode Pengembangan Sistem}

Metode yang digunakan untuk pengembangan sistem adalah prototype [8]. Tahap-tahap pengembangannya adalah:

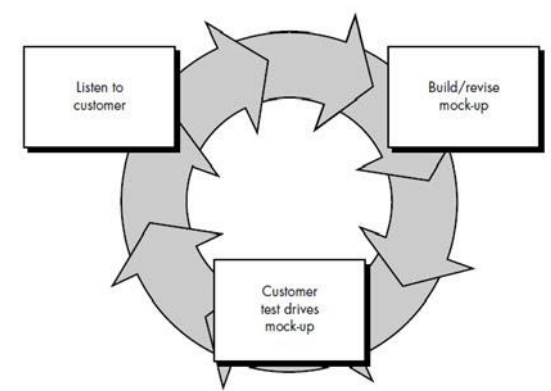

Gambar 1. Model Prototype

a. Listen to Customer (Mendengarkan Pelanggan)

Pada tahap ini merupakan identifikasi kebutuhan user, proses ini dilakukan agar diperoleh informasi mengenai permasalahan yang terjadi dalam pembuatan sistem. Data dari permasalahan tersebut yang nantinya menjadi acuan untuk dilakukan proses pencarian solusi dan pengembangan pada tahap selanjutnya

b. Build and Revise Mock-up (Membangun dan Memperbaiki Prototype)

Setelah kebutuhan sistem terkumpul, maka akan dilakukan proses perancangan prototype seperti perancangan sistem dengan menggunakan UML yang meliputi use case diagram, activity diagram, sequence diagram.

c. Customer Test Drives Mock-up (Pengujian Prototype)

Pada tahap ini akan dilakukan pengujian terhadap prototype sistem yang telah dibuat, serta mengevaluasi apakah prototype sistem yang sudah dibuat sudah sesuai dengan yang diharapkan. Apabila dari hasil pengujian prototype tersebut belum sesuai kebutuhan maka dilakukan proses perbaikan ulang prototype sampai prototype tersebut menjadi sistem yang akhir dan benar-benar diterima atau sesuai dengan keinginan user. Proses pengujian prototype sistem nantinya menggunakan teknik pengujian black box.

\subsection{Gambaran Sistem}

Aplikasi AR animasi gambar pada baju akan dibuat aplikasi yang berbasis android dimana nantinya pengguna akan dapan mengscan marker yaitu berupa desain sablon yang ada pada baju agar dapat menampilkan visual animasi objek 3D pada gambar sablon, metode marker based sendiri berarti sistem memerlukan marker sebagai cara untuk mentrigger objek 3D yang ada sehingga penyablon akan menambahkan desain tambahan sebagai markernya, dengan dibuatnya aplikasi ini diharapkan dapat membuat hasil sablon memiliki kesan modern dan membantu menarik minat konsumen

\subsection{Kebutuhan Sistem}

Kebutuhan sistem yang digunakan dalam pembuatan aplikasi AR animasi gambar pada baju:

1. Kebutuhan Marker

Menyediakan marker sebagai cara untuk mentrigger animasi 3D yang telah dibuat agar dapat 
ditampilkan pada layar smartphone dengan mengarahkan kamera ke arah marker, sistem akan memuat database dan mencocokan apakah marker tersedia atau tidak untuk diproses lebih lanjut ke tahap penampilan objek animasi 3D.

2. Kebutuhan User

Untuk dapat menikmati animasi 3D, user harus memiliki marker dalam bentuk gambar cetak baik berupa sudah tersablon pada kaos atau gambar print sehingga penampilan objek animasi dapat stabil, smartphone sebagai alat scanner dan instalasi aplikasi.

\section{Kebutuhan Output}

Output yang dihasilkan sistem yaitu berupa animasi 3D yang dapat bergerak diatas marker.

\subsection{Arsitektur Sistem}

Arsitektur sistem aplikasi AR animasi gambar pada baju seperti gambar 2 .

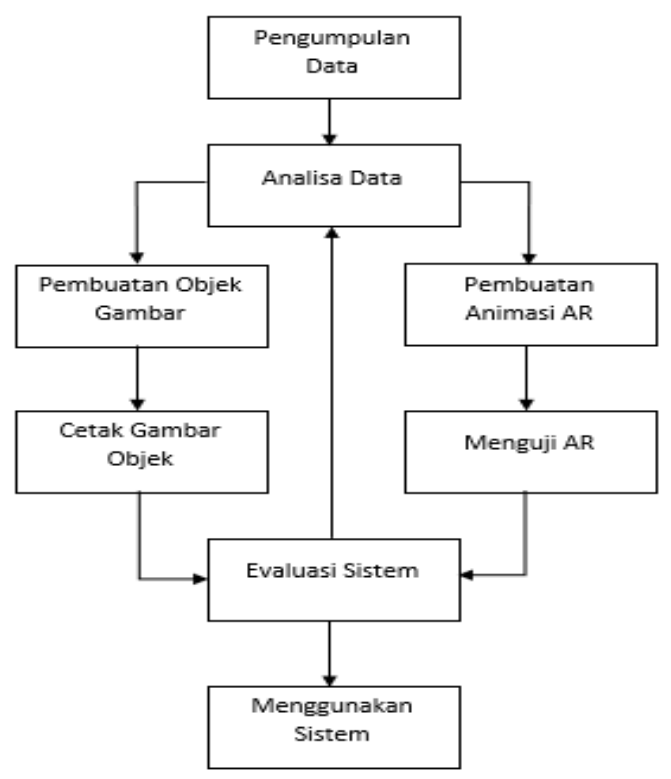

Gambar 2. Arsitektur Sistem

Langkah-langkah pembuatan aplikasi AR animasi gambar pada baju yaitu

1. Pengumpulan Data

Pada tahap ini pengumpulan informasi terkait gambar objek, animasi AR, software dan hardware yang akan digunakan selama penelitian.

2. Analisa Data

Analisa data dilakukan agar bahan yang akan digunakan benar sudah sesuai dengan yang dibutuhkan dan persiapan melakukan tahap pengerjaan selanjutnya.

3. Pembuatan Objek Gambar dan Pembuatan Animasi AR

Pada tahapan ini peneliti membuat gambar yang akan dijadikan objek sebagai animasi AR dan pembuatan animasi AR.

\section{Cetak Gambar Objek dan Menguji AR}

Setelah gambar objek jadi maka akan dilakukan proses cetak berupa penyablonan gambar ke kaos dan pengujian AR dilakukan pada hasil sablon pada kaos.

\section{Evaluasi Sistem}

Pada tahapan ini dilakukan evaluasi sehingga dapat disimpulkan hasil jika tidak sesuai dengan yang diharapkan maka akan memulai kembali proses analisa data untuk memperbaiki project.

6. Menggunakan Sistem

Tahapan selesai apa bila hasil sesuai dengan yang diharapkan.

\section{HASIL DAN PEMBAHASAN}

\subsection{Use Case Diagram}

Use case diagram mendeskripsikan kebutuhan sistem dari sudut pandang pengguna, berguna untuk membantu memahami kebutuhan [9].

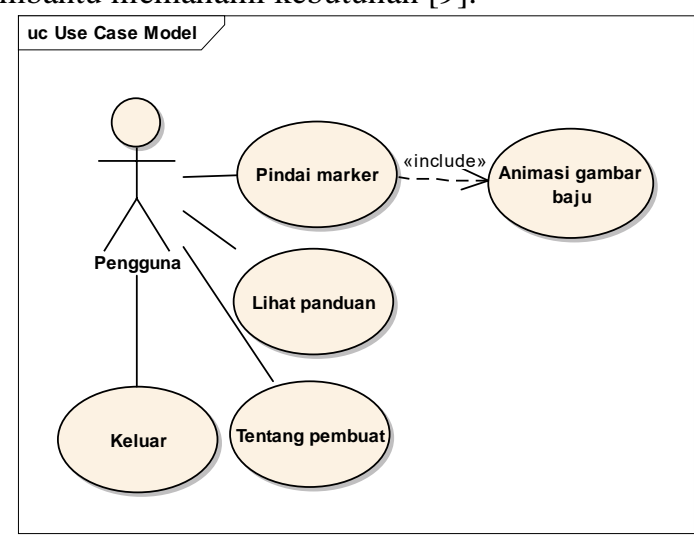

Gambar 3. Use Case Diagram

Gambar 3 menjelaskan pengguna melakukan pemindaian marker pada sistem kemudian sistem akan menampilkan animasi gambar baju dalam bentuk 3 dimensi. Pengguna juga dapat melihat panduan penggunaan sistem, melihat profil pembuat sistem atau keluar dari sistem.

\subsection{Activity Diagram}

Activity Diagram adalah diagram yang mendeskripsikan aliran aktivitas dari use case [9].

\section{a. Pindai Marker}

Activity diagram pindai marker pada aplikasi AR animasi gambar pada baju seperti gambar 4.

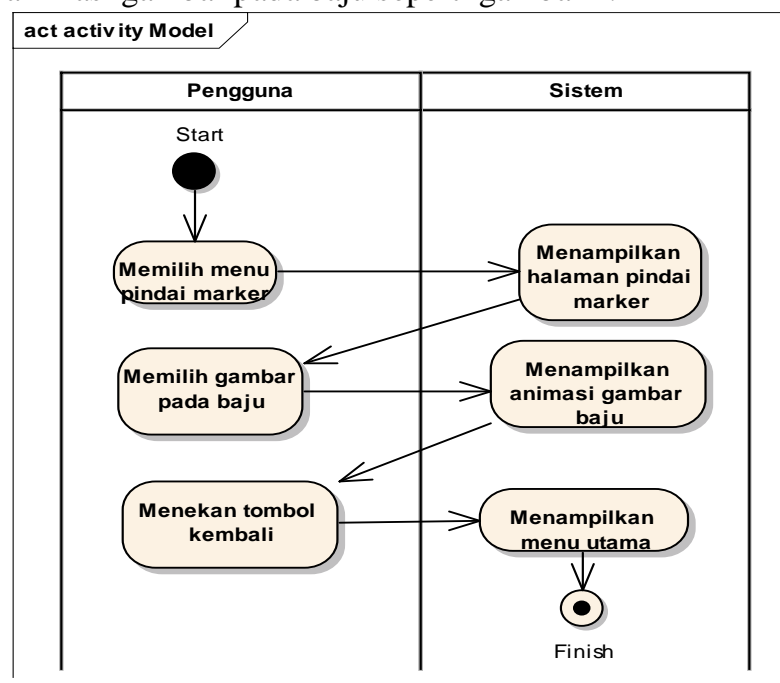

Gambar 4. Activity Diagram Pindai Marker 
Gambar 4 menjelaskan pengguna memilih menu pindai marker pada istem kemudian sistem akan menampilkan halaman pindai marker. Pengguna memilih gambar yang ingin dilihat animasi pada baju kemudian sistem akan menampilkan animasi gambar pada baju dalam bentuk 3 dimensi. Untuk kembali ke menu awal, pengguna dapat menekan tombol kembali yang tersedia pada sistem.

\section{b. Lihat Panduan}

Ativity diagram lihat panduan pada aplikasi AR animasi gambar pada baju seperti gambar 5 .

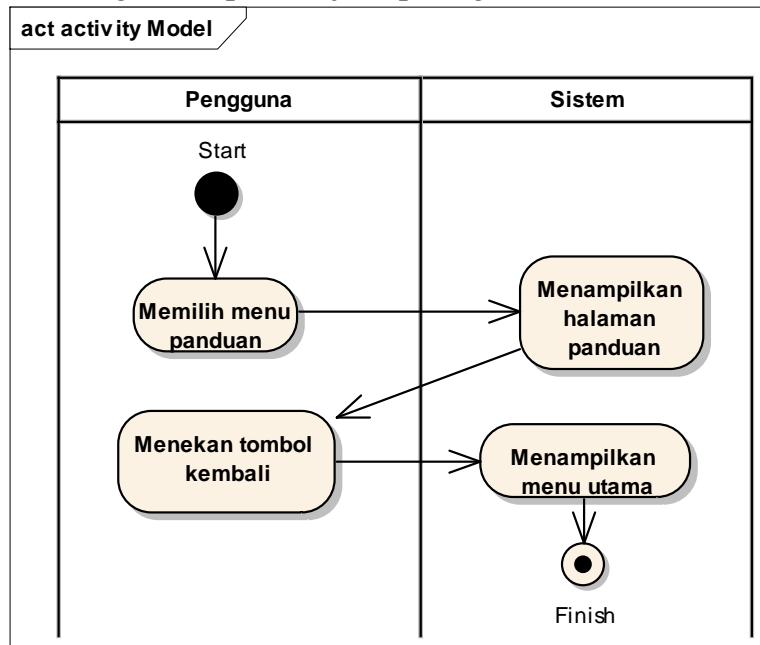

Gambar 5. Activity Diagram Lihat Panduan

Gambar 5 menjelaskan pengguna memilih menu panduan pada sistem kemudian sistem akan menampilkan halaman panduan. Untuk kembali ke menu awal, pengguna dapat menekan tombol kembali yang tersedia pada sistem.

\section{c. Tentang Pembuat}

Activity diagram tentang pembuat pada aplikasi AR animasi gambar pada baju seperti gambar 6 .

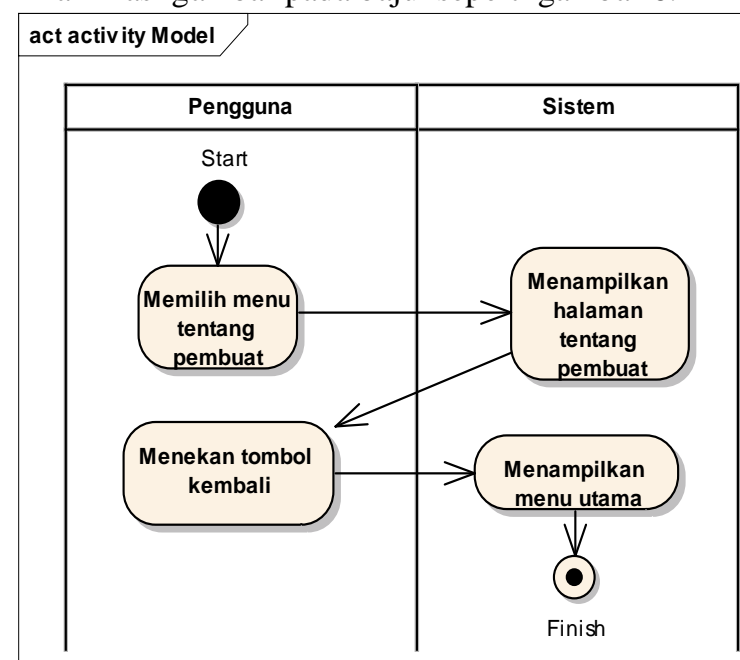

Gambar 6. Activity Diagram Tentang Pembuat
Gambar 6 menjelaskan pengguna memilih menu tentang pembuat pada istem kemudian sistem akan menampilkan halaman tentang pembuat yang berisi profil pembuat sistem. Untuk kembali ke menu awal, pengguna dapat menekan tombol kembali yang tersedia pada sistem.

\subsection{Sequence Diagram}

Sequence Diagram merupakan diagram yang tersusun dari rangkaian waktu [9].

a. Pindai Marker

Sequence diagram pindai marker pada aplikasi AR animasi gambar pada baju seperti gambar 7 .

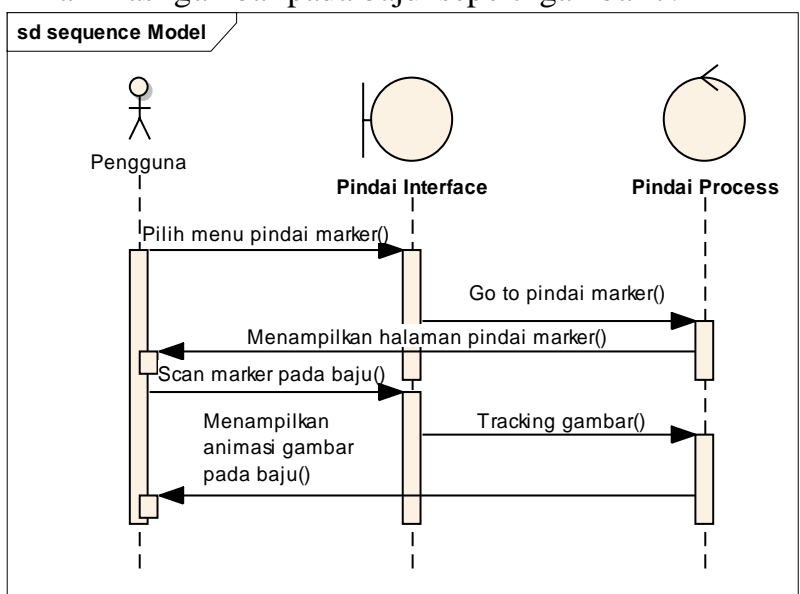

Gambar 7. Sequence Diagram Pindai Marker

Gambar 7 menjelaskan pengguna memilih menu pindai marker pada sistem kemudian sistem akan menampilkan halaman pindai marker. Pengguna memilih gambar yang ingin dilihat animasi pada baju kemudian sistem akan menampilkan animasi gambar pada baju dalam bentuk 3 dimensi.

b. Lihat Panduan

Sequence diagram lihat panduan pada aplikasi AR animasi gambar pada baju seperti gambar 8 .

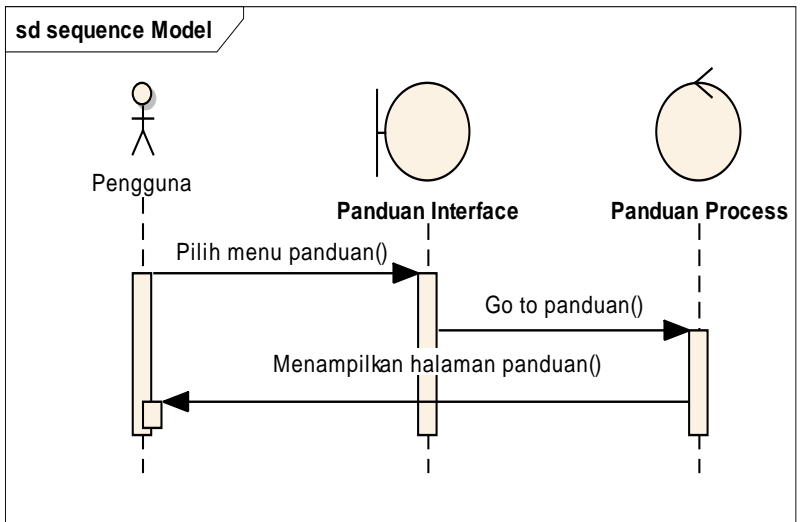

Gambar 8. Sequence Diagram Lihat Panduan

Gambar 8 menjelaskan pengguna memilih menu panduan pada sistem kemudian sistem akan menampilkan halaman panduan. 


\section{c. Tentang Pembuat}

Sequence diagram tentang pembuat pada aplikasi AR animasi gambar pada baju seperti gambar 9. Gambar 9 menjelaskan pengguna memilih menu tentang pembuat pada istem kemudian sistem akan menampilkan halaman tentang pembuat yang berisi profil pembuat sistem

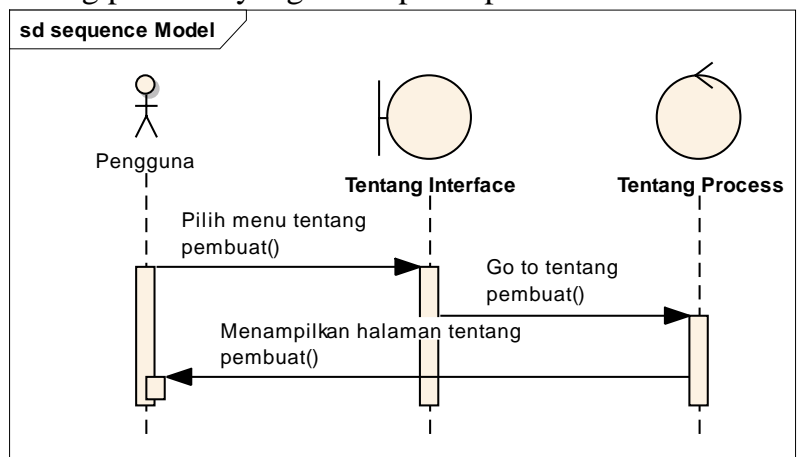

Gambar 9. Sequence Diagram Tentang Pembuat

\subsection{Implementasi}

a. Pembuatan Gambar

Gambar dibawah merupakan tampilan pembuatan gambar untuk image objek dengan menggunakan Corel Draw.

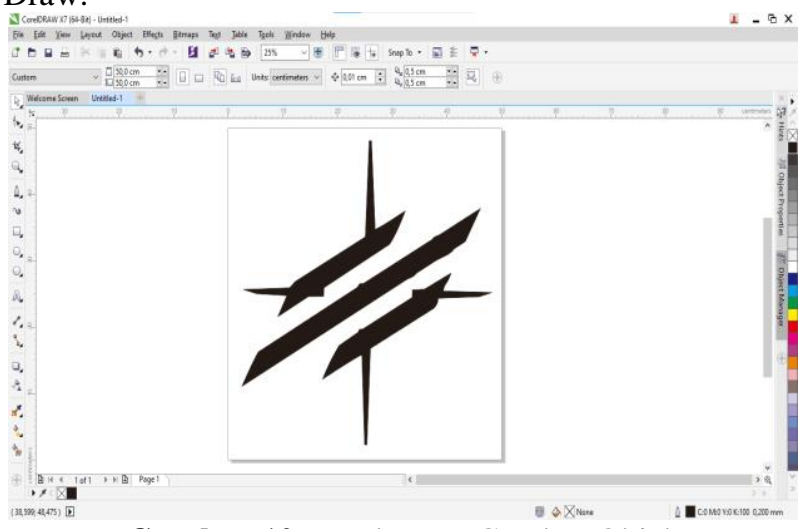

Gambar 10. Pembuatan Gambar Objek

\section{b. Pembuatan Lisensi}

Gambar dibawah merupakan tampilan pembuatan lisensi aplikasi pada web vuforia

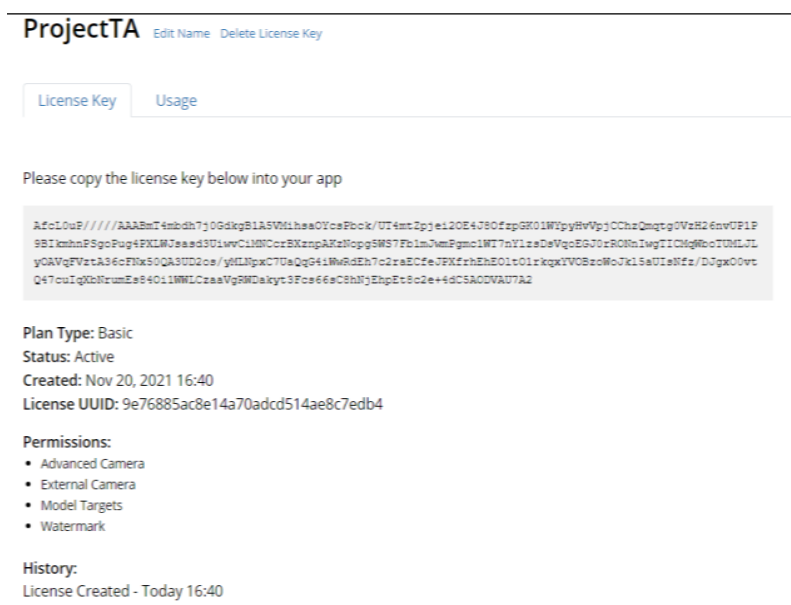

Gambar 11. Pembuatan Lisensi c. Pembuatan Database Image

Gambar dibawah merupakan tampilan pembuatan database image objek dengan menggunakan vuforia

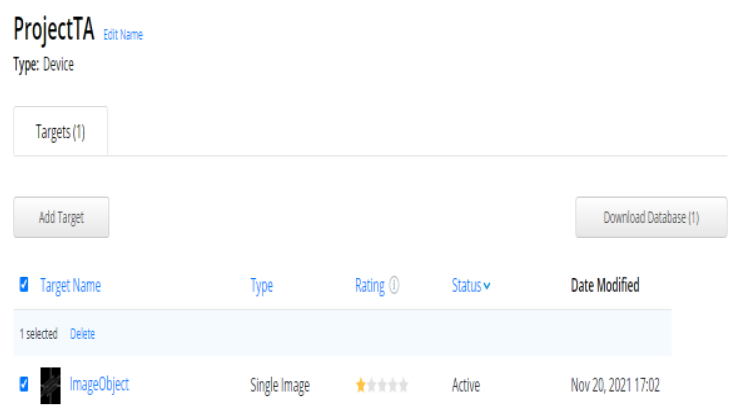

Gambar 12. Pembuatan Database Image

d. Pembuatan Image Objek

Gambar dibawah merupakan tampilan proses pembuatan image objek di unity3D dengan AR Camera dan vuforia engine

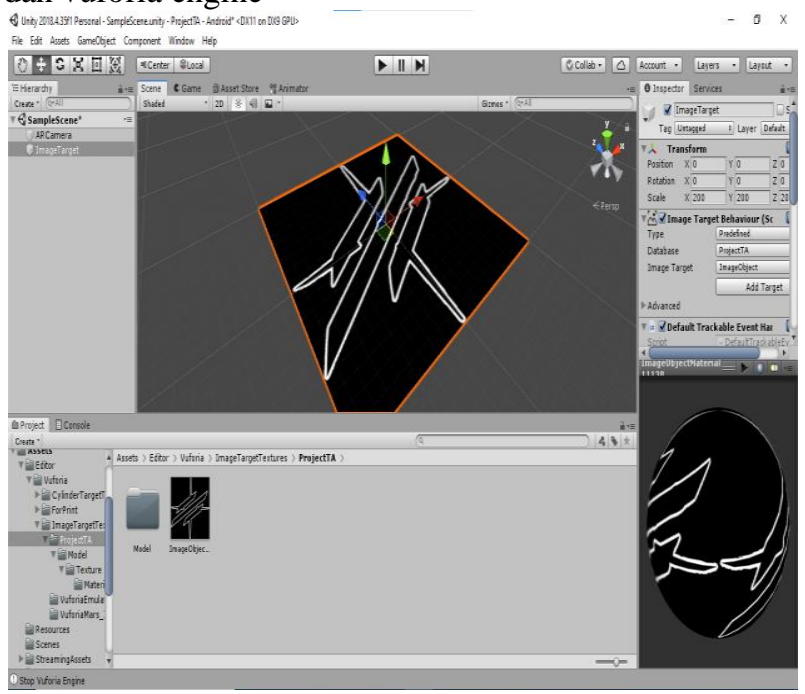

Gambar 13. Pembuatan Image Objek

e. Pembuatan Animasi

Gambar dibawah merupakan tampilan proses pembuatan penambahan animasi 3D pada image objek di unity3D dengan AR Camera dan vuforia engine

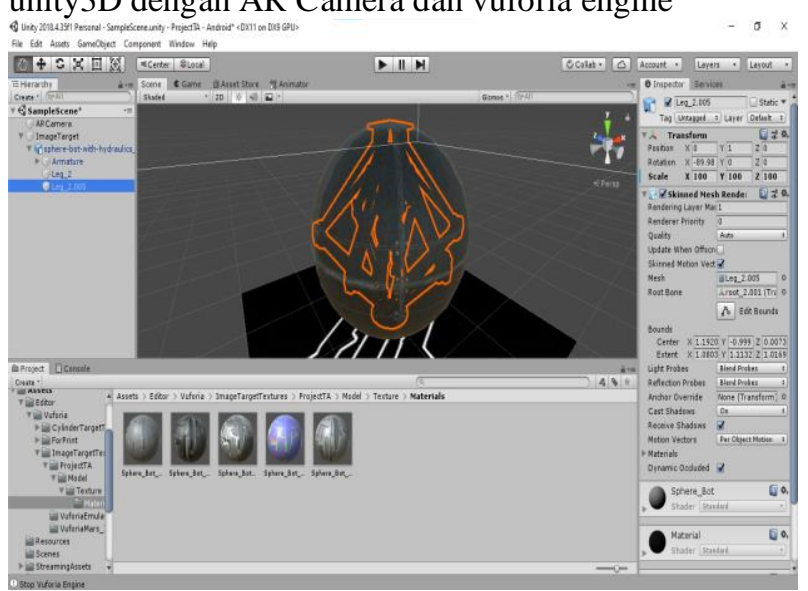

Gambar 14. Pembuatan Animasi 


\section{f. Test Run}

Gambar dibawah merupakan tampilan proses menjalankan aplikasi AR di unity3D dengan AR Camera dan vuforia engine

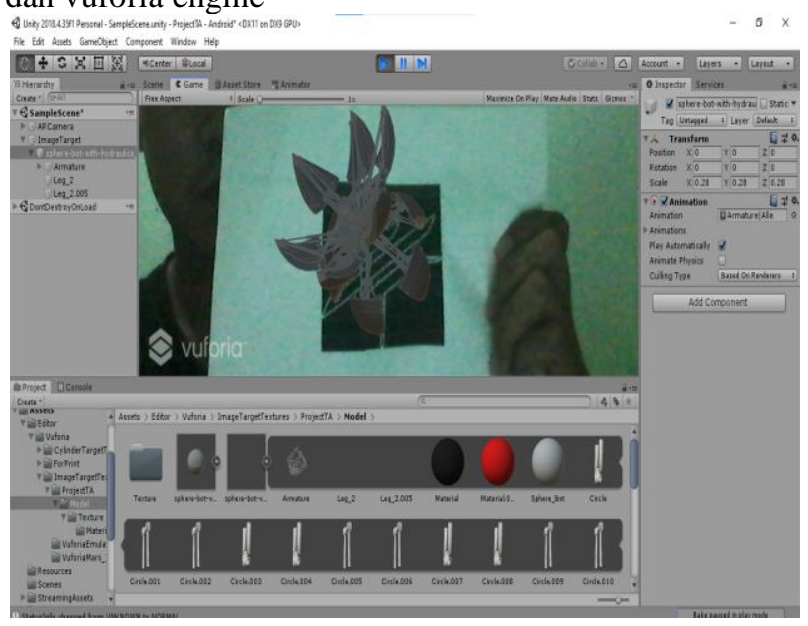

Gambar 15. Test Run

\section{g. Build Aplikasi}

Gambar dibawah merupakan tampilan proses membangun aplikasi AR di unity3D dengan AR Camera dan vuforia engine agar bisa dijalankan di smartphone android.

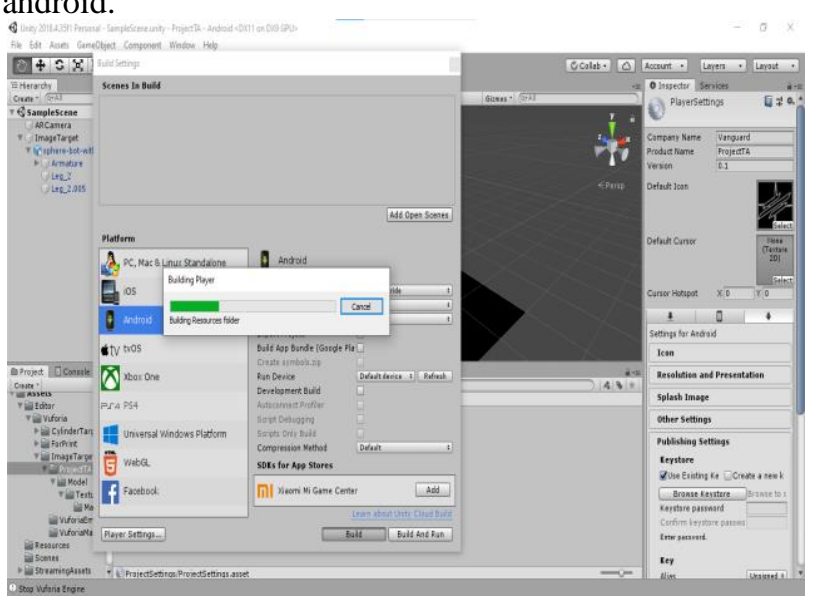

Gambar 16. Build Aplikasi

\section{h. Hasil Running}

Gambar diatas merupakan tampilan proses menjalankan aplikasi AR yang dijalankan di smartphone android

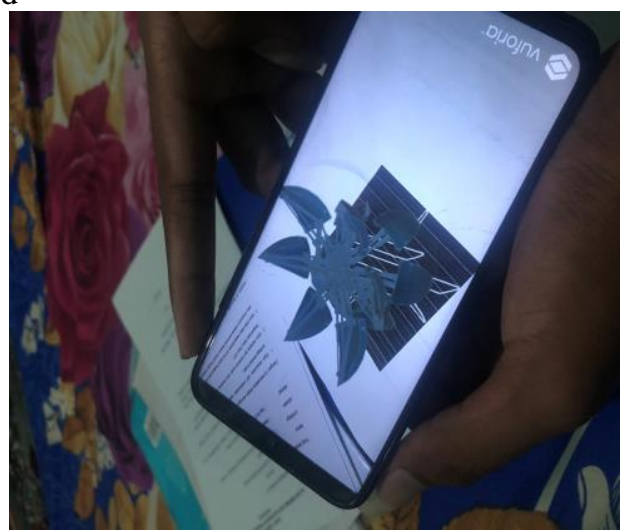

Gambar 17. Hasil Running i. Pengujian Black Box

Pengujian aplikasi AR animasi gambar pada baju dengan metode black-box diperlihatkan seperti tabel 1 .

Tabel 1. Tabel Pengujian Black-Box

\begin{tabular}{cllll}
\hline Input & \multicolumn{1}{c}{ Fungsi } & Output & Hasil \\
\hline \multirow{2}{*}{ Menu } & Untuk & Tampilan & \\
& menampilkan & halaman & Berhasil \\
& menu sistem & menu & \\
& $\begin{array}{l}\text { Untuk melakukan } \\
\text { Tampilan }\end{array}$ & \\
Pindai & pemindaian & halaman & \\
Marker & marker & pada & pindai & Berhasil \\
& gambar & marker & \\
& Untuk melihat & Tampilan & \\
Lihat & panduan & halaman & \\
Panduan & penggunaan & lihat & Berhasil \\
& sistem & panduan & \\
& Untuk melihat & Tampilan & \\
halaman & \\
Tentang & profil pembuat & tentang & Berhasil \\
Pembuat & aplikasi & pembuat & \\
& & Keluar & \\
& & dari & Berhasil \\
Keluar & Keluar dari sistem & sistem &
\end{tabular}

Dari hasil pengujian dapat disimpulkan untuk uji black box yang meliputi uji input, proses dan output dengan acuan rancangan perangkat lunak telah terpenuhi dengan hasil sesuai rancangan.

\section{KESIMPULAN}

Kesimpulan yang diambil dari aplikasi AR animasi gambar pada baju yaitu Aplikasi AR animasi gambar pada baju dengan teknologi Augmented Reality dapat membuat konsumen untuk tertarik dalam membeli baju, objek pada aplikasi AR animasi gambar pada baju dapat ditampilkan dengan 3 dimensi. Hasil pengujian menggunakan blackbox testing sesuai dengan fungsi dari aplikasi yang dibuat.

\section{DAFTAR PUSTAKA}

[1] Muntahanah, Rozali Toyib, and Miko Ansyori, "Penerapan Teknologi Augmented Reality Pada Katalog Rumah Berbasis Android (Studi Kasus PT. Jashando Han Saputra)," J. Pseudocode, vol. 4, pp. 81-89, Feb. 2017.

[2] Tarmin Abdulghani and Bambang Plasmana Sati, "Pengenalan Rumah Adat Indonesia Menggunakan Teknologi Augmented Reality Dengan Metode Marker Based Tracking Sebagai Media Pembelajaran," Media J. Inform., vol. 11, pp. 43-50, Jun. 2019.

[3] Adam Raihan Fadhlurrahman, Fauziah, and Aris Gunaryati, "Augmented Reality Pengenalan Landmark Negara Asia Tenggara Menggunakan Algoritma FAST Corner Dan Natural Feature Tracking," J. Tek. Inform. Dan Sist. Inf., vol. 8, pp. 1012-1016, Sep. 2021. 
[4] Pemanfaatan Augmented Reality Sebagai Media Pembelajaran, "Ilmawan Mustaqim," J. Pendidik. Teknol. Dan Kejuru., vol. 13, pp. 174-183, Jul. 2016.

[5] Mestilia Meilin Mongilala, Virginia Tulenan, and Brave A. Sugiarso, "Aplikasi Pembelajaran Interaktif Pengenalan Satwa Sulawesi Utara Menggunakan Augmented Reality," J. Tek. Inform., vol. 14, pp. 465-474, Desember 2019.

[6] Dhiyaa Hilmy Yusuf, Ady Purna Kurniawan, and Anang Sularsa, "Perancangan Marker Kartu DAN UI Pada Aplikasi Pembelajaran Alfabet Bilingual Berbasis Augmented Reality," E-Proceeding Appl. Sci., vol. 6, pp. 2707-2714.

[7] Ayyu Faridhatul Masrura, M. Farras Aditya P. A., Muhammad Hussein Isron, Dodik Arwan Dermawan, and Paramitha Nerisafitra, "Aplikasi Edukasi Berbasis Android Menggunakan Augmented Reality," Explore IT 12, pp. 29-36, 2020.

[8] Agus Mulyanto, Sistem Informasi Konsep \& Aplikasi. Yogyakarta: Pustaka Pelajar, 2014.

[9] Munawar, Analisis Perancangan Sistem Berorientasi Objek dengan UML (Unified Modeling Language). Bandung: Informatika, 2018. 